\title{
LA CONTROVERSIA EN TORNO A ANTONIO VENDETTI (1699-1796), UN PLATERO Y BRONCISTA ENTRE ROMA Y MADRID. LA IMPORTANCIA DEL DIBUJO Y DEL MODELADO COMO EXPRESIÓN Y HABILIDAD DE LOS PLATEROS EN EL SIGLO XVIII
}

\author{
Teresa Leonor M. Vale \\ Universidade de Lisboa
}

Data recepción: 2017/03/03

Data aceptación: 2018/04/24

Contacto autora: teresalmvale@gmail.com

ORCID: https://orcid.org/0000-0003-1711-5245

\section{RESUMEN}

Antonio Vendetti nació en Cottanello, en el año de 1699 y ejerció su actividad profesional en Roma, ciudad donde obtuvo la patente de platero en 1737. Desde esa ciudad trabajó para el rey de Portugal, D. Juan V (1689-1750), llamado el Magnánimo y uno de los más importantes comitentes del barroco romano, realizando dos juegos de sacras para la real capilla de S. João Baptista de la iglesia de S. Roque de Lisboa. Durante veinte años -en concreto, entre 1759 y 1779-vivió en España, país al que legó un conjunto significativo de obras en plata y en bronce.

En este texto tenemos la intención de acercarnos a la figura de Antonio Vendetti y a las obras que dejó en España y Portugal, pero también considerar la destreza de los plateros del siglo XVIII en el dibujo y el modelado. Nos ocuparemos también de la controversia pública que rodeó a este platero en 1756, en la medida en que ello nos permitirá discutir la importancia de dichas habilidades para el ejercicio del oficio de platero en este período.

Palabras clave: platero, broncista, barroco, Vendetti

\section{ABSTRACT}

Antonio Vendetti was born in Cottanello in 1699 and pursued his career in Rome, where he qualified as a silversmith in 1737. It was from Rome that Vendetti worked for John $V$ of Portugal (John the Magnanimous, 1689-1750), one of the most important patrons of Roman Baroque, and created two sets of altar canons for the royal chapel of Sao João Baptista in the church of Sao Roque, Lisbon. Between 1759 and 1779, Vendetti lived in Spain, bequeathing a significant number of silver and bronze works to the country.

In this text I will attempt to analyse the figure of Antonio Vendetti and the works he left in Spain and Portugal, while also discussing the drawing and modelling skills of 18th-century silversmiths. In addressing these issues, I shall also focus on the 1756 controversy involving Vendetti, in terms of the extent to which it allows us to discuss the importance of these skills to silversmiths of that time.

Keywords: silversmith, bronzesmith, Baroque, Vendetti 


\section{Introducción}

Antonio Vendetti nació en Cottanello, en el año de 1699 y ejerció su actividad profesional en Roma, ciudad donde obtuvo la patente de platero en 1737. Desde esa ciudad trabajó para el rey de Portugal, D. Juan V (1689-1750), Ilamado el Magnánimo y uno de los más importantes comitentes del barroco romano, realizando dos juegos de sacras para la real capilla de S. João Baptista de la iglesia de S. Roque de Lisboa. Durante veinte años -en concreto, entre 1759 y 1779- vivió en España, país al que legó un conjunto significativo de obras en plata y en bronce.

En este texto tenemos la intención de acercarnos a la figura de Antonio Vendetti y a las obras que dejó en España y Portugal, pero también considerar la destreza de los plateros del siglo XVIII en el dibujo y el modelado. Nos ocuparemos también de la controversia pública que rodeó a este platero en 1756 , en la medida en que ello nos permitirá discutir la importancia de dichas habilidades para el ejercicio del oficio de platero en este período.

La importancia del dibujo y del modelado en el diseño y la ejecución de la obra en la platería barroca'

En los talleres de los orfebres y plateros en general, y en los del barroco romano en particular, además de las materias primas y las herramientas de trabajo, existieron otros útiles esenciales para el ejercicio de su profesión: dibujos, grabados y modelos. Considerando los objetivos que nos hemos propuesto, nos ocuparemos de los primeros y de los últimos.

En relación a los dibujos, lo primero que debemos considerar es que una vez realizado el encargo de una pieza de plata, el siguiente paso era su diseño. Contar para ese momento con diseños anteriores era de vital importancia.

Como se sabe, por regla general, las obras de los plateros romanos del siglo XVIII presentan, además de la marca de Roma (de la Reverenda Camera Apostolica), la del platero que realizó en su momento la pieza, pudiéndose así establecer de forma automática su autoría. Pero para poder identificar con precisión las personas que participaron en el proceso de elaboración de estas piezas, especialmente aquellas con un carácter escultórico más evidente, deben identificarse múltiples contribuciones, que corresponden a una mayor cantidad de fases, a menudo, de diversos actores. A saber: quién proporcionaba los dibujos (el propio platero o otros, pintores, escultores o arquitectos), quién producía los modelos y quién efectuaba de hecho la pieza en plata², siendo necesario a veces, en el caso de esta última fase, identificar a más de un platero cuando el trabajo requería intervenciones específicas y especializadas. Por último, no se debe dejar de lado el papel del comitente.

En relación al dibujo de la pieza, éste formaba parte de una primera etapa, en la que se daba forma a la idea inicial y a los requisitos eventualmente establecidos por el comitente. Como ya se ha mencionado, el dibujo, o los dibujos, que servían como base para llevar a cabo el trabajo, podían pertenecer al propio platero, a otro platero, o a un artista, escultor, pintor o arquitecto, diferente. El diseño, con miras a la realización de una pieza de plata, podría incluso ser proporcionado por el comitente -que salvaguardando algunas excepciones, no era el autor- hecho "a suo gusto" o "a suo genio"; expresiones coetáneas, de uso frecuente, que pretenden traducir la participación del cliente en la idea y en el diseño de la obra?

Como ejemplo, se puede mencionar a finales del siglo XVIII, el envío de dibujos desde Lisboa para que fueran tomados en cuenta por los orfebres de la ciudad papal a la hora de realizar los cálices para la basílica de Nossa Senhora e Santo António de Mafra: el primer gran encargo de platería en Roma por orden del rey $D$. Juan $V$ de Portugal. En este caso, la decisión del comitente de realizar y enviar a Roma tales dibujos tenía como objetivo principal proporcionar información específica sobre los aspectos que deberían ser respetados en la morfología de los cálices (de acuerdo a los criterios establecidos por S. Carlos Borromeo en su obra Instructionum fabricae et Supellectilis Ecclesiasticae ${ }^{4}$, y no tanto proveer a los orfebres de indicaciones de carácter ornamental o incluso iconográfico. Pero, en otros casos, el comitente que proporcionaba dibujos al platero buscaba intervenir precisamente sobre ese otro tipo de aspectos. 
La primera posibilidad, entre las que se han indicado anteriormente en relación a la autoría de los dibujos que servían como base para la elaboración de la obra, aquella en la que el platero era el autor, sería probablemente la más común $y$, de hecho, se conocen numerosos ejemplos dentro de la producción romana. Sin embargo, debe tenerse en cuenta que en ocasiones se asume que el platero es su artífice porque no se han encontrado, asociados a esa misma pieza, dibujos de otro autor (o noticia de los mismos). Esta circunstancia, no es óbice para que consideremos la importancia en número de los dibujos realizados por el propio platero en el momento de elaborar una pieza.

Un aspecto concreto que revela la importancia del diseño en el proceso de ideación y realización de la obra de un platero, es la inclusión sistemática del valor económico que corresponde a su realización (al igual que sucede con los modelos) en las cuentas presentadas por los plateros que trabajaban para Portugal durante el reinado de D. Juan V (1706-1750) y que, junto con los respectivos asientos de pago, se incorporaron a los libros de cuentas de la embajada de Portugal en Roma, que se conservan en la Biblioteca da Ajuda (Lisboa).

Los dibujos de los plateros, así dice Peter Führing, son muy poco conocidos en el ámbito de la historia del dibujo y ocupan un espacio marginal en este campo. Sin embargo "Chaque feuille constitue -en dehors de son intérêt purement esthétique- un point de départ pour I'historien pour comprendre le rôle du dessin dans l'élaboration du projet d'orfèvrerie, de sa conception à son exécution. Dès que nous comprenons que l'orfèvre peut être un dessinateur remarquable et qu'il doit être capable de sculpter pour réaliser ses propres modèles en trois dimensions, il paraît logique que l'intérêt pour la sculpture se traduise dans ses dessins. Le sculpteur n'est alors pas exclusivement celui qui exécute des sculptures en marbre, en pierre ou en terre cuite, mais aussi l'orfèvre qui maîtrise des matériaux autrement précieux comme l'argent et l'or"

Los dibujos producidos por los plateros, en el contexto de sus talleres, tenían características específicas ${ }^{6}$ que traducen las necesidades de sus autores a la hora de crear materialmente la pieza.
Sin embargo, estos dibujos de carácter proyectivo no fueron los únicos que se realizaron, y pueden reconocerse, en los talleres del Setecientos. También debemos referirnos a la existencia de dibujos elaborados para la presentación de la pieza al comitente; muy diferentes, desde el punto de vista de su funcionalidad, y por ello también en su apariencia, en relación con los dibujos proyectivos. Mientras que los primeros se guardaban generalmente en el taller, los segundos podían ser trasladados a la residencia del comitente, un hecho que, combinado con el carácter a veces desechable de los dibujos proyectivos, explica la supervivencia más frecuente de los dibujos de presentación. Por otro lado, el carácter más acabado de estos últimos contribuyó a su valoración y apreciación por los coleccionistas del siglo XIX. Ejemplo de esto es el llamado Álbum Weale, que hemos tenido la oportunidad de estudiar en los últimos años?.

Entre los que consideramos bocetos o dibujos proyectivos, estrechamente relacionados con la concepción, diseño y ejecución de una pieza, hay que distinguir diferentes tipos de diseños, que corresponden a otras tantas etapas del proceso. Entre todos, se identifican de inmediato los bocetos, los cuales simplemente toman nota de una idea para uso (casi) exclusivo del autor -que pueden ser más o menos elaborados y, a menudo, ser objeto de añadidos en más de un momento (buscando una mejor definición de la idea). Otro tipo de dibujo es el que está destinado a ser compartido en el taller, de manera que por lo general presenta un mayor detalle. En conjunto, éstos son los dibujos que permiten que la pieza sea comprensible a otros ojos y no solo a los de su autor. Son dibujos que circulan dentro del taller $y$, a veces, entre varios talleres (como ocurrió con los grabados).

Merece la pena que nos detengamos un poco en esta última posibilidad, la de que el diseño pudiera ser empleado por más de un platero. De hecho, diferentes artífices podían trabajar a partir de un mismo dibujo, como resulta evidente al considerar las piezas que han sobrevivido. Este es el caso de Antonio Gigli (c. 1704-1761?) y Leandro Gagliardi (1729-1804) en la realización de la naveta y del incensario de la capilla de $\mathrm{S}$. João Baptista de la iglesia de S. Roque en Lisboa. 
Antonio Gigli había realizado la naveta y el incensario que formaban parte del llamado "serviço para a missa", pero habiendo sido ofrecidas las dos piezas, por voluntad del rey $D$. Juan $V$ de Portugal, al Papa Benedicto XIV (que a su vez las había ofrecido a la catedral de S. Pietro, en su ciudad natal de Bolonia, en cuyo Tesoro se pueden hoy contemplar), el platero Leandro Gagliardi realizó otro incensario y naveta basados en los mismos dibujos y en todo idénticos a los de Gigli. A pesar de que pueden ser reconocidas diferencias en la calidad técnica, como sucede en relación a la plasticidad de las piezas, podemos concluir que éstas son genéricamente idénticas.

Otro ejemplo, incluso más instructivo, es el de los treinta candelabros de plata dorada, destinados a la Exposición del Santísimo en la misma capilla de Lisboa, realizados por un conjunto de seis plateros diferentes, todos siguiendo el mismo diseño de Giovanni Felice Sanini (1727-1787)8.

Debe hacerse también alusión a los dibujos de obras de arte ya existentes y que funcionaban como una referencia para las nuevas piezas. Este es el caso de varias esculturas en plata que reproducen, a partir de la realización de dibujos (a la que seguiría, la elaboración del modelo), estatuas a veces mucho más grandes y de diferentes materiales. Se puede mencionar como ejemplo, entre otros muchos, el diseño elaborado en el prestigioso taller romano Valadier, y que podemos datar entre 1790 y 1795, de parte de la Flagelación de Alessandro Algardi (1595-1654), que debió tener como propósito servir para la realización de una obra que ya no existe o no ha sido aún localizada', que podemos considerar como perteneciendo al príncipe Giovanni Torlonia (1754-1829), cliente asiduo de Giuseppe Valadier (1762-1839), entonces jefe del taller de la familia ${ }^{10}$.

Por último, podemos destacar la complejidad que rodea al papel desempeñado por el dibujo en el proceso de creación, sobre la que acertadamente ha llamado la atención Jennifer Montagu, cuando reflexiona sobre la cuestión de la autoría de las piezas: "We have seen Giardini combining his own designs with reliefs taken from the paintings of others, Barchi working from a drawing by Luzi, and Gagliardi working from models by the sculptor Maini. There were many different ways of making sculptural silver and there was room for the many forms of collaboration between the silversmith and those who provided the designs or the models, just as between the principale (as the head of a workshop was called) and those who worked under him. Are we therefore justified in stating that these works were "by" Giardini, Barchi or Gagliardi? Of course we are; but I happen to be more interested in the complicated relationships between the numerous men actually involved in producing these marvelous works of art." "1.

La fase siguiente a la plasmación de una idea en el dibujo, con el fin de producir una obra de platería, era la que correspondía a la elaboración de uno o más modelos de la pieza, y permitían el paso de la bidimensionalidad a la tridimensionalidad.

Lo que hasta aquí se ha referido, en relación a la autoría de los dibujos, puede aplicarse del mismo modo a los modelos. También éstos podrían ser realizados por el propio platero o por otro artista, a menudo un escultor.

Los modelos en cera, yeso, cobre o madera, ya fueran elaborados por los plateros o por escultores, constituyen una presencia constante en los talleres, como dan fe los inventarios conocidos $^{12}$. La abundancia de modelos en los talleres de plateros romanos, en la primera mitad del siglo XVIII, y también el hecho de que éstos fueran a veces propiedad común de varios talleres ${ }^{13}$, ayuda a explicar la similitud reconocible entre piezas de diferentes autores, en particular en cuanto a las opciones adoptadas al nivel del lenguaje ornamental y de algunas soluciones compositivas ${ }^{14}$. Esta propiedad común se puede explicar por los lazos familiares existentes entre miembros de distintos talleres, lazos que son de sobra conocidos y sobre los que no faltan referencias documentales.

Por otra parte, incluso antes de cualquier consideración sobre la realización de modelos diseñados específicamente para la fabricación de una pieza de plata por escultores y otros artistas, se debe tomar en cuenta que los inventarios que conocemos de los talleres de plateros de los siglos XVII y XVIII revelan la existencia de obras de escultura (a menudo en bronce, pero también en otros materiales), que muy probablemente no serían simples obras de arte del patrimonio del dueño del taller, sino que funcionarían como modelos 
para sus propios trabajos ${ }^{15}$; una circunstancia que debió contribuir también a que varios autores adoptaran soluciones similares en sus trabajos.

Asimismo, como prueba documental evidente de la importancia de los modelos en el proceso de fabricación de una pieza de platería, pueden considerarse las cuentas presentadas por el propio platero, en las que figura un montante que corresponde a la realización de los modelos (coste de las materias primas utilizadas, etc. ${ }^{16}$.

Fueran los modelos diseñados por los propios plateros o por escultores, su presencia en los talleres de platería del siglo XVIII era obligatoria, como podemos concluir no sólo de la lectura de los inventarios mencionados, y del análisis de las cuentas a las que también se ha hecho referencia, sino también por otro tipo de documento particularmente elocuente: los retratos de los plateros, en los que estos profesionales son representados en su entorno de trabajo, y en los que no es infrecuente la presencia de los modelos ${ }^{17}$.

\section{La controversia en torno al platero Anto- nio Vendetti}

\section{El platero Antonio Vendetti}

Antonio Vendetti nació en Cottanello, en Sabina en 1699, pero desarrolló su actividad artística en Roma a los largo de dos extensos períodos, entre 1737 y 1760 y desde 1780 hasta la fecha de su muerte, en 1796.

Vendetti había comenzado su formación muy joven. Existen evidencias documentales de que entre 1713 y 1717 se encontraba ya trabajando en el taller de Giovanni Francesco Arrighi (16461730) y que, desde 1723, fue registrado como oficial.

Entre los años 1721 y 1725 residió en una casa de la manzana de Santa Lucía. El 4 de mayo de 1737 adquirió el taller de Miguel Ángel Raimondi en Via del Pellegrino, incluyéndose en la compra todos los utensilios y todas las piezas de plata que se hallaban entonces en el taller (copones, cálices, relicarios, etc.), por un importe de doscientos escudos.

Vendetti obtuvo la patente de platero finalmente el 29 de septiembre de1737 (habiendo sido admitido a las pruebas el 23 de agosto) y durante los tres años siguientes continuó residiendo con su mujer, Vittoria Ricci, en el mismo edificio de la Via del Pellegrino donde se encontraba también su taller. Entre 1744 y 1746, ocupó el cargo de $4^{\circ}$ Cónsul de la corporación de los plateros romanos y entre 1749 y 1753 , el de $3^{\circ}$ Cónsul. Entre los años 1754 y 1758 vivió con su familia, en Strada dei Banchi Nuovi, ubicándose allí también el taller.

El 18 de junio de 1758, Antonio Vendetti figura como ausente en su taller, que habría sido alquilado al platero Bartolomeo Delicati de Perugia. Con toda probabilidad, Vendetti ya habría iniciado su viaje a España, formando parte seguramente del grupo de artistas que componían el séquito de Carlos III, que en ese momento dejaba atrás Nápoles y se preparaba a ocupar el trono español. Se sabe que en 1760 Vendetti estaba ya en ese país, en concreto en Barcelona (donde había atracado la embarcación que trasladaba al mencionado monarca y a su séquito). Allí trabajaría durante algún tiempo con el platero catalán Manuel Pratdesaba18, trasladándose en 1761 a Madrid, donde operaría en los círculos de la Casa Real, bajo la dirección del arquitecto italiano Francesco Sabatini (1722-1797). A las obras realizadas por Vendetti en España dedicaremos una particular atención más adelante.

Entre 1781 y 1793 Antonio Vendetti -que había regresado a la ciudad papal en 1780- residió con su esposa en Via Giulia, al lado de la iglesia de S. Biagio della Pagnotta. Con él trabajaba su hijo Angelo, también platero. Vendetti murió a la edad de 97 años en su casa de Via Giulia, el 9 de septiembre de $1796^{19}$.

Entre las obras de Antonio Vendetti identificadas hasta ahora en Italia, se cuentan las siguientes:

- Un cáliz de plata de los años cuarenta, que lleva la marca del platero, pero no la marca de Roma (denominado "Camerale", de la Reverenda Camera Apostolica). La pieza, propiedad de la iglesia romana de Santo Spirito in Sassia, está dotada de un componente escultórico notable, especialmente a nivel de la base ${ }^{20}$.

- Encuadernación de un libro hebreo (plata fundida, relevada y cincelada) que lleva el 

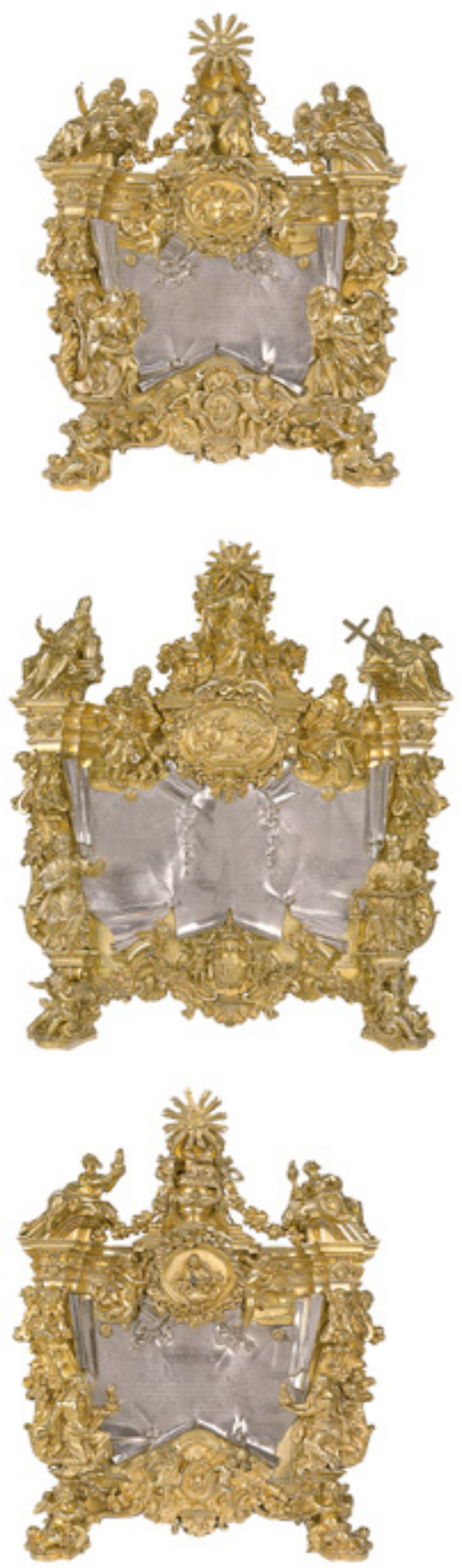

Fig. 1. Antonio Vendetti (1699-1796), Roma, 1751-1752. Juego de sacras de uso solemne en la capilla de $S$. João Baptista de la iglesia de $\mathrm{S}$. Roque. Plata y plata dorada, cincelada e incisa. Museu de S. Roque, Lisboa (Inv. MPr18, MPr19, MPr20). () Museu de S. Roque, SCML, Lisboa
"Camerale" No 116, por lo que se puede fechar entre los años 1746 y $1748^{21}$. Colección privada.

- Un cáliz de plata perteneciente al monasterio de Santa Clara de Urbania, con la marca de Roma N $N^{\circ} 110 a$, correspondiente a los años 1740 a $1742^{22}$.

- Tres sacras, en plata y plata dorada, con la marca de Roma, correspondiente al bienio 1749-1751, que figura en la colección del Museo Diocesano de Urbania²3.

- Un cáliz en plata, propiedad de la iglesia de S. Elpidio al Mare (Ascoli Piceno), con el "Camerale" $\mathrm{N}^{\circ} 119$, correspondiente al bienio $1751-1753^{24}$.

- Un busto relicario de San Biagio, en plata fundida, relevada y cincelada, que está en el Istituto delle Suore dell'Immacolata di Santa Chiara (Fiuggi) y que presenta la marca del platero y también la marca de Roma del año 176825; este último aspecto plantea algunos problemas de interpretación, teniendo en cuenta que en aquel año Vendetti estaba ausente de Roma.

\section{Obras destinadas a clientes portugueses}

Hasta el presente se identificaron las siguientes piezas de Antonio Vendetti destinadas a iglesias y clientes portugueses: seis sacras, tres en plata y plata dorada y tres en bronce sobredorado, destinadas para el uso ordinario y para el uso solemne, respectivamente, en la capilla de San João Baptista de la iglesia de S. Roque de Lisboa, (formando parte en la actualidad de la colección del Museu de S. Roque) y también un cáliz de plata dorada, de una colección privada.

Curiosamente las seis sacras ejecutadas por Antonio Vendetti no constan en el detallado documento titulado "Relação das pessas de Ouro, e prata, etc ${ }^{a}$, que se mandam vir de Roma para Serviço da nobilissima Capella do Espirito Santo e S. João Baptista da Igreja de S. Roque, e cazo de não virem antes que a Capella, a devem acompanhar" ${ }^{26}$, enviado desde Lisboa el 9 de marzo de 1744. Sin embargo, en diciembre de 1745 Antonio Vendetti recibió una cantidad en pago por un trabajo de platería no especificado 


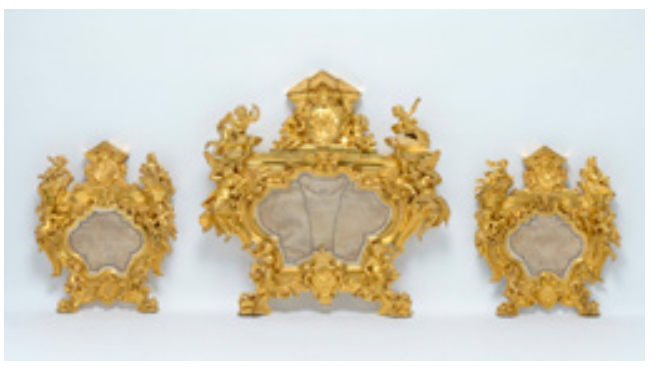

Fig. 2. Antonio Vendetti (1699-1796), Roma, c. 1745-1750. Juego de sacras de uso diario en la capilla de S. João Baptista. Bronce sobredorado y pergamino. Museu de S. Roque, Lisboa (Inv. MPr31, Mpr32, MPr33). (C) Museu de S. Roque, SCML, Lisboa

y, a partir de septiembre de 1746 y hasta marzo de 1750, comenzó a recibir regularmente pagos por la ejecución de las sacras. Se puede concluir por tanto que habría recibido la orden para la realización de las mismas, poco después de la fecha del citado documento en el que no aparecían mencionadas estas obras.

Las sacras destinadas a uso solemne, en la capilla de São João Baptista, son objetos complejos y excepcionales, tanto del punto de vista de su composición, como iconográfico, y también por la riqueza de los materiales (fig. 1).

El marco que rodea al texto -el componente principal de la función de la sacra- presenta una copiosa decoración de carácter arquitectónico. La sacra central, más grande, muestra el arquitrabe, soportado por pilastras, en el centro del cual se observa un medallón, de forma elíptica, en el que aparece representada la institución de la Comunión, rodeada por las virtudes teologales (fe, esperanza y caridad). Sobre las pilastras, se observan alegorías del Pontificado y la Iglesia. Adosadas a los fustes, se nos presentan las figuras de Melquisedec y Aarón. Por su parte, la base presenta unos pies laterales formados por tornapuntas decoradas con ángeles tenantes de las armas reales portuguesas, dispuestas en el centro. Dotadas de una solución compositiva idéntica a la de la sacra central, aunque en una versión simplificada, las sacras del Evangelio y la Epístola, tienen un encuadre cuadrangular. La sacra del Evangelio muestra, en el arquitrabe, un medallón con la figura de San Juan Evangelista, enmarcado por el Cordero Pascual y una alegoría de la Providencia y putti (quizás sean ángeles). En el tronco

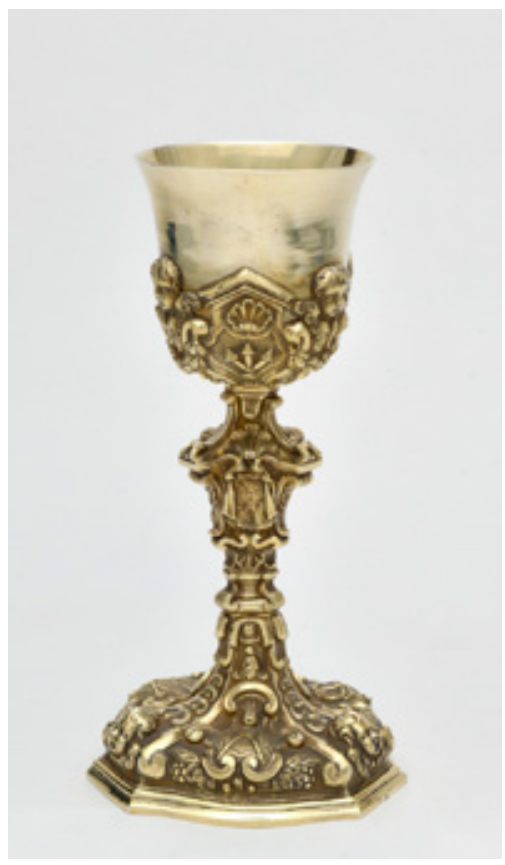

Fig. 3. Antonio Vendetti (1699-1796), Roma, 1750-1751. Cáliz. Plata y plata dorada, fundida, relevada y cincelada. Colección privada

de las pilastras se observan representaciones de los Patriarcas. Conchas y guirnaldas completan la decoración. En el centro de la base puede contemplarse un medallón ovalado flanqueado por querubines con una representación del Fénix renaciendo de las cenizas. La sacra de la Epístola presenta, en el arquitrabe, un medallón con la figura del Ecce Homo, en el que se reconoce una alusión a Pilatos (Lavabo) y una alegoría de la Atemporalidad. El eje de las pilastras está animado por la presencia de ángeles y arcángeles. En el centro de la base aparece un medallón ovalado flanqueado por putti (quizás sean ángeles), con una representación del pelícano alimentando a las crías, figuración simbólica del amor materno y paterno e incluso de Cristo Crucificado.

También se encargó al platero Antonio Vendetti, un segundo conjunto de sacras, destinado para el uso diario en la misma capilla (fig. 2). Fabricadas en bronce sobredorado y con los textos en pergamino, estas tres sacras son, desde nuestro punto de vista, más interesantes por el dinamismo del enmarcado que, al ser menos complejo y con un programa iconográfico me- 

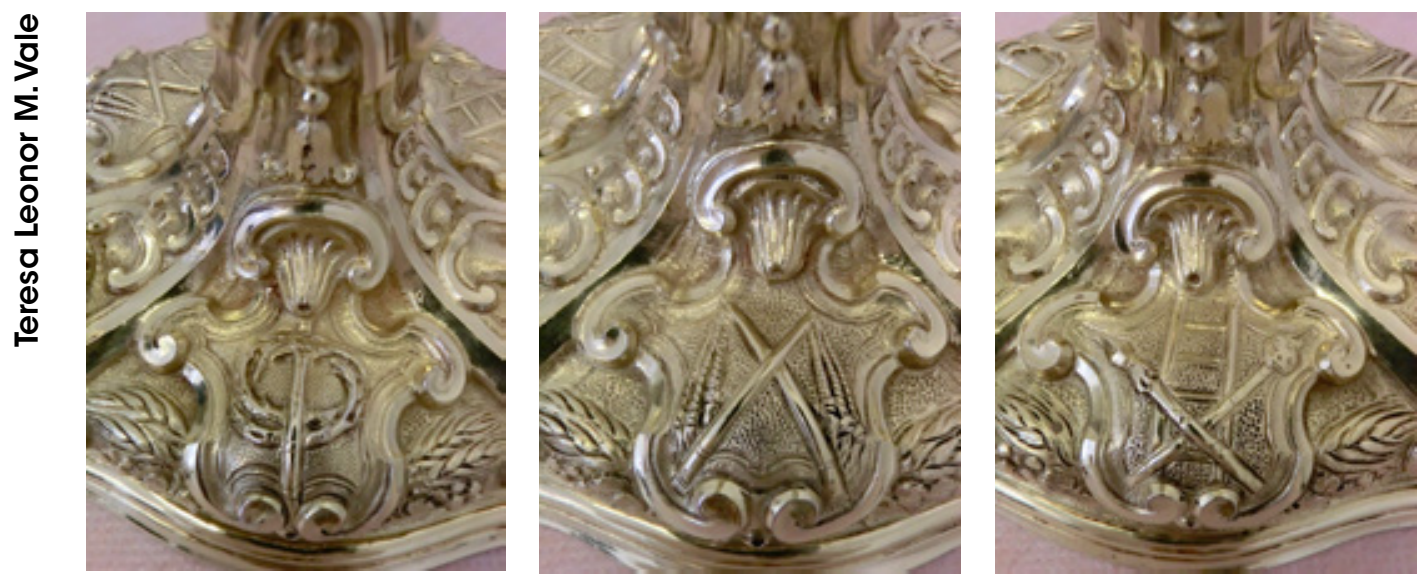

Figs. 4 a, b y c. Antonio Vendetti (1699-1796), Roma, 1750-1751. Cáliz (detalles). Plata y plata dorada, fundida, relevada y cincelada. Colección privada

nos denso, se revela más característico del gusto barroco, con una buena alternancia rítmica de perfiles contracurvados y animados por figuras con un gran movimiento.

La sacra central, más grande, muestra el arquitrabe, soportado por pilastras, y en el centro del cual se ve un medallón de forma sustancialmente circular rematado por un frontón triangular, con una figuración de Moisés y el retorno a la Tierra Prometida. El texto (en el centro) está encuadrado por un marco mixtilíneo y flanqueado por ángeles revoloteando. La base presenta pies laterales decorados con ángeles. En la parte central se observan las armas reales portuguesas.

Las sacras del Evangelio y la Epístola presentan una solución de composición idéntica a la de la sacra central, aunque en una versión simplificada. La figura de San Juan Evangelista aparece en el medallón principal de la sacra del Evangelio, en tanto que en el centro de la base de esta sacra se reconoce un medallón oval con una representación del pelícano alimentando a sus crías. La sacra de la Epístola presenta en el medallón principal la figura de San Juan Bautista y en el centro de la base una representación del Fénix que renace de las cenizas²7.

Antonio Vendetti es también el autor de un cáliz que ahora forma parte de una colección privada portuguesa (fig. 3). Es un cáliz con la copa lisa, ligeramente acampanada y gollete recortado, con decoración relevada, con áticos [ornato en forma de un frontón triangular sin base] y cabezas de querubines. En la alineación de los áticos se reconocen representaciones de símbolos de la pasión de Cristo: los clavos, los dados, el martillo y las tenazas. El astil tiene nudo de sección triangular, con forma de pirámide invertida, decorado con volutas y símbolos de la Pasión: la Verónica, la columna y la túnica. El pie, mixtilíneo, se presenta compartimentado en secciones animadas alternativamente por querubines y la representación en alto relieve de los símbolos eucarísticos (maíz y uvas) y de la pasión (vergajo y lanza) (figs. 4 a, b y c). La patena es circular, también en plata dorada y sin ningún tipo de decoración.

El cáliz lleva las marcas del platero y la marca de Roma, correspondiente al bienio 1751-175228.

También con destino a Portugal, Vendetti habría realizado un incensario (en forma de templo), siendo su comitente el arzobispo de Braga. En la medida en que no nos ha sido posible encontrar más información acerca de esta pieza ${ }^{29}$, esta es la única información que tenemos. Así, solamente podemos proponer como hipótesis ser el comitente el arzobispo en cuestión D. Gaspar de Braganza (1716-1789), hijo legitimo del rey $D$. Juan $\vee$ y prelado en Braga entre 1758 y la fecha de su muerte.

\section{La obra realizada en España}

Después de una breve estancia en Barcelona, Antonio Vendetti marchó a Madrid. Este viaje debió producirse a finales de 1761, pues el 
documento que recoge el que, probablemente, puede considerarse su primer trabajo en la capital española, está datado el 14 de febrero del año siguiente. De hecho, esta misma fecha aparece en el contrato firmado con miras a la realización, por parte de Vendetti, de la componente en bronce (dos leones y la balanza que porta la figura de la alegoría de la Justicia) del suntuoso sepulcro del rey Fernando $V^{\mid 31}$, en la iglesia de Santa Bárbara de Madrid, más conocida por Salesas Reales, según diseño de Sabatini.

Durante ese año y a lo largo de los que le sucedieron -en particular entre 1762 y 1771- la actividad de Vendetti se desarrolló bajo el denominado Servicio Real, es decir, la Casa Real española, trabajando principalmente como metalista [aquel que trabaja con metales no preciosos] y específicamente broncista, y no tanto como platero. De hecho, la documentación que varios investigadores españoles han sacado a la luz, recoge, fundamentalmente, los pagos que recibió por la realización de ornatos de bronce para muebles de los palacios reales de El Pardo, Aranjuez y El Escorial $^{32}$. También refleja esta documentación su actividad asociada a la realización de obras de carácter religioso, destinadas a la catedral Segovia, en plata y bronce, por encargo del rey Carlos III (dos ángeles, seis blandones, el dosel y la custodia para la Exposición del Santísimo) realizadas entre 1771 y $1773^{33}$ El Cabildo de la catedral debió quedar satisfecho con estos trabajos porque en 1775 encargaba al mismo Vendetti el chapado en plata de una imagen gótica de la Virgen de la Paz y la realización del respectivo sillón y basamento ${ }^{34}$.De todas las obras que hizo para la catedral segoviana se conservan los blandones (1773); la guarnición de la imagen escultórica de la Virgen de la Paz, con el sillón y el basamento incluidos (1775); y el dosel, marcado en 1776 . En cambio, no han llegado hasta nuestros días los dos ángeles ni la custodia. No obstante, es probable que también sean obras suyas el sagrario, la grada y el frontal del altar mayor, realizados en mármol y bronce en torno a 1775, según el diseño de Francesco Sabatini ${ }^{35}$.

Aunque se ha identificado la realización de algunas obras de plata, la actividad de Vendetti, especialmente entre los años 1762 y 1771, se desarrolló predominantemente en el círculo de la

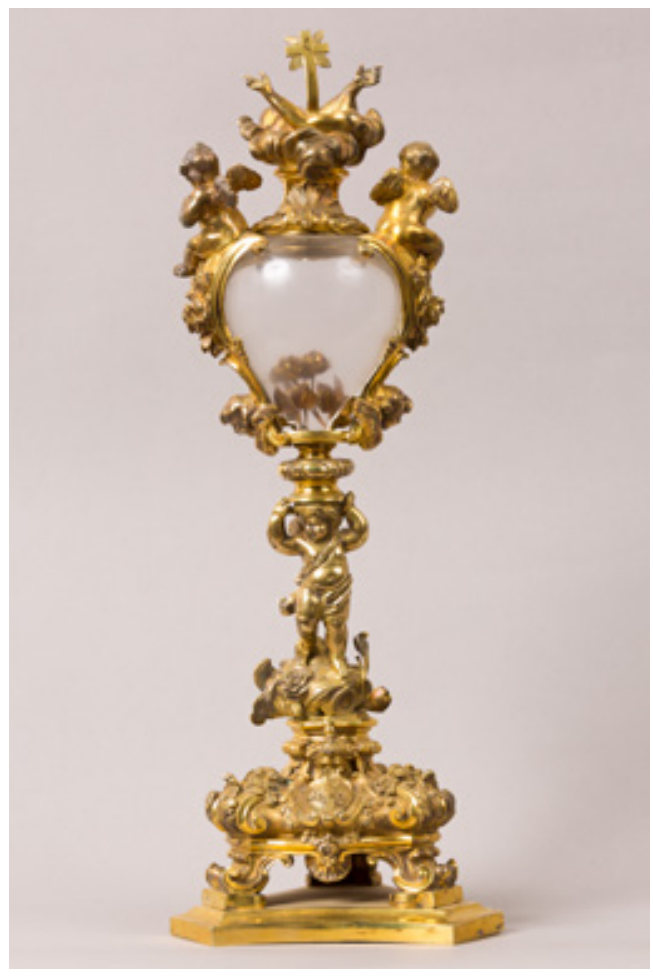

Fig. 5. Antonio Vendetti (1699-1796), Madrid, 1772. Relicario, plata y bronce sobredorado. Palacio Real, Madrid (Inv. B4248850). (C) Patrimonio Nacional

Casa Real y en el contexto de la metalística, ${ }^{36}$ originando "lo que más tarde se denominará el taller de bronces, que funcionará a partir de esa fecha, bajo la dirección de Juan Bautista Ferroni" ${ }^{37}$.

Los desacuerdos con compañeros de trabajo determinaron que Vendetti fuera apartado de las obras reales, aunque seguramente siguió haciendo ciertos trabajos, como atestigua la documentación ${ }^{38}$.

El platero italiano aún contaba con un taller activo en Madrid, dentro del cual llevaría a cabo obras de plata, entre las cuales pueden referirse como ejemplo, entre muchos otros, el relicario datado en 1772, que pertenece al Palacio Real de Madrid $^{39}$ (fig. 5), o el cáliz de 1773, de la iglesia parroquial de la Natividad de Nuestra Señora de San Martín de la Vega ${ }^{40}$ (que muestra algunas similitudes con el cáliz de Lisboa antes mencionado ${ }^{41}$ ) (figs. 6 a y b). Estas obras debieron realizarse sin duda con la colaboración de diferentes oficiales, varios de ellos aprendices y probable- 

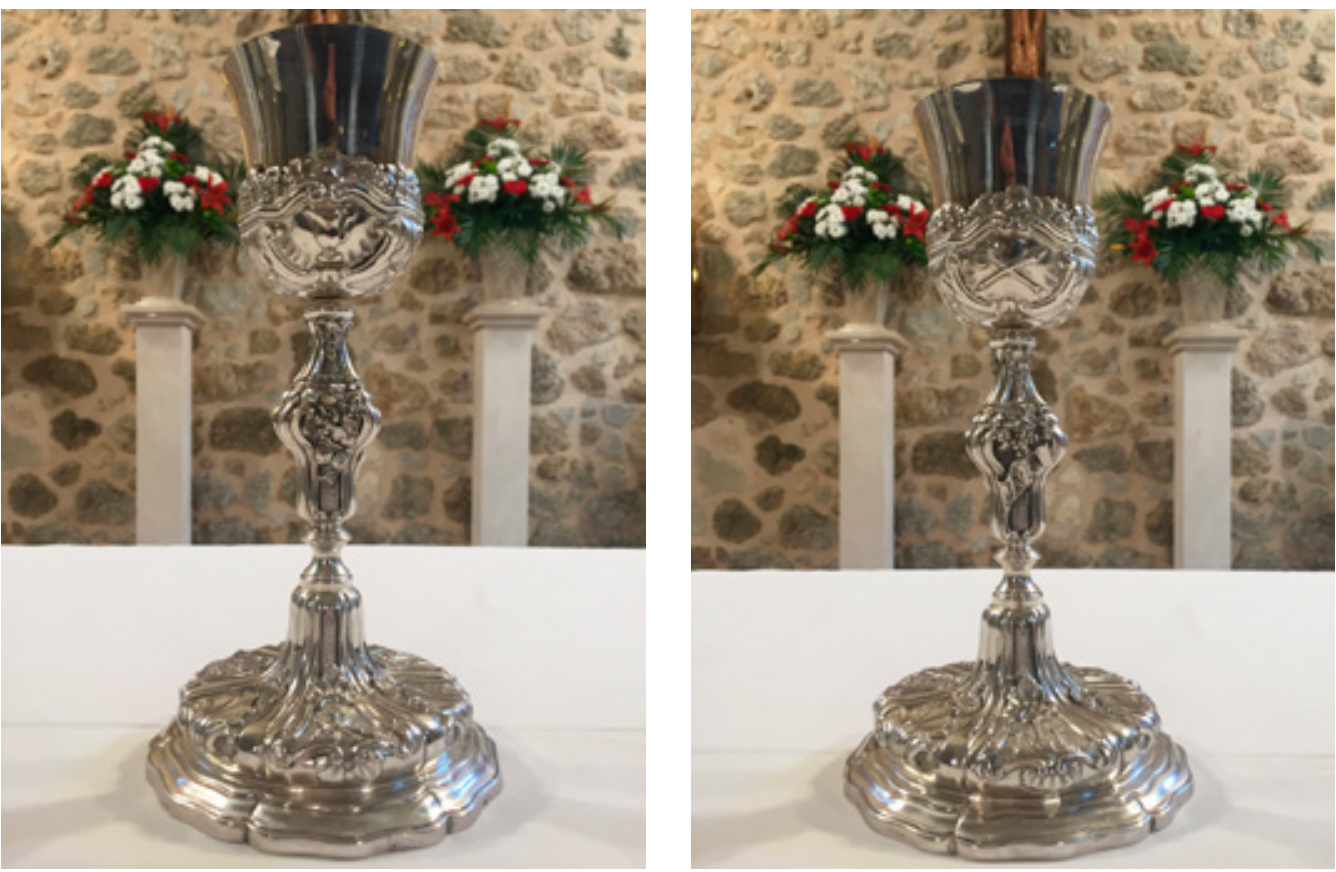

Figs. 6 a y b. Antonio Vendetti (1699-1796), Madrid, 1773. Cáliz, plata torneada, fundida, relevada y cincelada. Iglesia parroquial de la Natividad de Nuestra Señora, San Martín de la Vega. Dos vistas

mente venidos desde Barcelona, como sugieren sus nombres catalanes ${ }^{42}$.

Asimismo, participaron en el taller de la familia, los hijos Angelo y más tarde Carlo. Este último había nacido en Roma en 1751 y murió en Madrid, en lo que sería la residencia madrileña de los Vendetti, ubicada en la Carrera de San Jerónimo, el 8 de marzo 1773, siendo enterrado en la iglesia de San Sebastián ${ }^{43}$.

La prosperidad del taller parece haberse ido degradando poco a poco, una circunstancia a la que no habría sido ajena la salida de Antonio Vendetti del círculo de encargos reales. En los años 1778 y 1779 el platero italiano solicitó el apoyo de la furriera de Madrid, ayuda que le fue negada ${ }^{44}$.

Como ya mencionamos, Vendetti regresó a Roma en 1780 y murió dieciseis años más tarde en su casa de Via Giulia.

\section{La controversia}

El 1 de diciembre de 1756, los plateros Giovanni Bettati (c. 1700-1777) y Giacomo Franci- si (1715-después de 1787) declararon bajo juramento que Antonio Vendetti era incapaz de realizar, por si mismo, el modelo y los dibujos, por lo que cada vez que eran necesarios, para la elaboración de una pieza, solicitaba el servicio de "professori" capaces, como Lorenzo MoreIli (1702-1784) y Luigi Landinelli. En particular, hacían referencia a que en la sacra realizada por Vendetti para la capilla de S. João Baptista de Lisboa, había sido necesario substituir varios elementos figurativos debido a su mala calidad, que fueron elaborados por Lorenzo Morelli, quien habría hecho 23 piezas para este fin ${ }^{45}$.

No pueden pasarse por alto las circunstancias en las que se produjo la declaración de estos dos plateros sobre las habilidades de Vendetti. La declaración jurada se había realizado en el contexto de una demanda presentada por la viuda del fundidor y platero Giuseppe Gagliardi (1697-1749), Costanza Fattori, y sus hijos, entre los cuales se encontraba el heredero del taller del padre, Leandro Gagliardi (1729-1804). La demanda recogía sus reclamaciones ante la falta de pago, por parte de la corona portuguesa, por el trabajo que habían realizado durante el reinado de $\mathrm{D}$. Juan $\vee$ de 
Portugal para la capilla de S. João Baptista de la iglesia de San Roque y para la basílica Patriarcal de Lisboa.

Cabe señalar que, tras la muerte del último embajador del rey Magnánimo en Roma, Manuel Pereira de Sampaio (1691-1750), el 13 de febrero de 1750 (en el puerto de Civitavecchia, al tiempo que acompañaba el embarque de obras de arte para Lisboa), y también la del propio soberano, en el último día del mes de julio del mismo año, la situación en Roma experimentó cambios profundos. Inmediatamente, la ausencia del embajador determinó que fuera el padre jesuita Antonio Cabral a Roma a ocuparse de los asuntos nacionales, incluyendo los encargos de obras de arte y todos los pagos que aún estaban en curso. Siguiendo sin duda las directrices de Lisboa, Antonio Cabral trató de reducir todos los gastos relativos a los pagos debidos a los artistas, llegando la negociación a buen término con algunos de ellos, pero no con todos. Este fue el caso de Gagliardi, que se consideraba perjudicado por las cantidades que, según había sido informado, recibirían como pago por el par de candelabros monumentales de la capilla de S. João Baptista, los cuatro relicarios realizados para la misma capilla ${ }^{46}$ y también por la imagen de Nuestra Señora de la Concepción, en plata dorada y escala 1/1, que se realizó para la basílica Patriarcal de Lisboa ${ }^{47}$.

En este contexto se desarrolló el proceso -minuciosamente estudiado y analizado por Jennifer Montagu ${ }^{48}$ - que se arrastraría por el camino lento de la justicia romana, durante muchos años y en el transcurso del cual Bettati y Francisi realizarían sus declaraciones sobre la incapacidad de Vendetti para el dibujo. Éstas deben ser interpretadas a la luz de las motivaciones que se encontraban detrás.

Antonio Vendetti se había convertido en el objetivo a batir desde el momento en que, junto con los plateros Simone Migliè (1679-1752), Bartolomeo Boroni (1703-1787) y Filippo Tofani (1694-1764), revisó las cuentas presentadas por Gagliardi para el segundo de los candelabros monumentales de la capilla de S. João Baptista, cuando éstos, muerto ya el embajador Pereira de Sampaio, en 1750, estaban listos para ser embarcados en el puerto de Civitavecchia ${ }^{49}$.
De los cuatro plateros, Vendetti era sin duda el menos conocido y prestigioso, por lo que es comprensible que resolvieran dirigir hacia él sus ataques en una estrategia de descrédito que, en última instancia, pretendía demostrar lo inadecuado de la revisión de cuentas que el platero había llevado a cabo. Esta práctica de revisión de las cuentas de un platero por sus compañeros de oficio, seguía siendo corriente y se conocen numerosas pruebas de eso en la documentación de la Biblioteca da Ajuda relativa a los encargos de D. Juan $\mathrm{V}$ de platería romana.

Otro detalle digno de mención para entender las declaraciones formuladas contra las habilidades de Vendetti en el contexto del caso presentado por Gagliardi, es que Giacomo Francisi era particularmente cercano a este último. Fue precisamente en el taller del fallecido Giuseppe donde, entre 1747 y 1749, había iniciado su actividad como joven cincelador. Tras la muerte del titular, Francisi continuó trabajando en el taller de la familia Gagliardi, bajo la dirección de Leandro.

Hay que llamar la atención también sobre el hecho de que, como muestra Costantino Bulgari, en la fecha de la muerte de Giuseppe el taller adeudaba a Francisi 105 scudi y 67 1 1/2 baiocchi romanos, por lo que este sería el primer interesado en la buena salud financiera de sus empleadores, para asegurar el mantenimiento de su empleo.

Por otro lado, también el platero Lorenzo Morelli, a quien ya hicimos referencia porque había sustituido, en el juego de sacras realizado por Vendetti para uso solemne en la capilla de S. João Baptista, las 23 partes presuntamente de más baja calidad, trabajó en los años 1748 a 1749 en el taller de Gagliardiso, lo que justificaría, por supuesto, su solidaridad con ellos.

Retomando el argumento del uso de dibujos y/o modelos por Vendetti, el contrato para la realización de lo que hasta ahora se cree que fue su primer trabajo en Madrid (la componente broncinea del mencionado monumento funerario de Fernando VI) efectivamente revela que el escultor Juan de León le había proporcionado unos modelos para la realización de dos grandes leones ${ }^{51}$.

Sin embargo, la cuestión de las habilidades de Vendetti no puede simplificarse. El mismo platero, fuera o no capaz de dibujar y modelar, 
aparece de forma clara y repetida, en las cuentas correspondientes a los trabajos de platería realizados por otros plateros para la capilla de $\mathrm{S}$. João Baptista, como un experto orfebre ${ }^{52}$. Este no habría sido el caso si el profesional en cuestión no fuera reconocido por su mérito. Antonio Vendetti, junto con Antonio Arrighi (1687-1776) y los ya mencionados anteriormente Simone Migliè, Bartolomeo Boroni y Filippo Tofani, eran los únicos plateros que tenían esta tarea de revisar las cuentas y ostentan sus estatutos de "Mastro Argentiere" o "Professore", en la extensa documentación que consultamos en la Biblioteca da Ajuda.

Si atendemos a las obras de Vendetti, que son sin duda el mejor testimonio de sus capacidades y habilidades, es innegable que la calidad al nivel de la plástica, sobre todo en las figuras, no es equivalente a los mejores ejemplos que se producen en el contexto romano para el período cronológico en cuestión. Pero esto no puede interpretarse como una falta de pericia en términos absolutos, a pesar de que no nos es dado saber si el trabajo realizado en las piezas de Vendetti se basó en dibujos suyos o de otro artista. Lo que nos parece indiscutible, siempre basado en la observación de las piezas que conocemos y estudiamos, es que los resultados son claramente mejores en las obras con menos componente escultórico.

De hecho, las obras más claramente decorativas y menos escultóricas -haciendo uso de estos términos meramente bajo una perspectiva operativa, para facilitar la comprensión de nuestro discurso- se presentan más equilibradas y muestran una alta calidad técnica de ejecución.

Este es exactamente el caso del cáliz que pertenece a una colección privada de Lisboa: si las cabezas de querubines que salpican el gollete no son suficientemente expresivas y presentan un volumen reducido, ya la base, con elaboradas cartelas, integrando representaciones relevadas de los instrumentos de la pasión de Cristo, denotan una alta calidad del cincelado y del tratamiento diferenciado de la superficie, lo que da dinamismo al todo, por los efectos de claroscuro obtenidos.

De vuelta a la vida de Antonio Vendetti, desconocemos por el momento los verdaderos motivos de su viaje a España en 1758 y de su permanencia en ese país hasta 1780, año en el que sabemos volvió a la ciudad pontificia; pero nos parece plausible que toda esta controversia, y sus posibles consecuencias, habrían contribuido para su ausencia de Roma durante casi dos décadas.

Por todo lo anterior, y dada la importancia del dibujo y del modelado en el ejercicio de la profesión de los plateros, al cual nos hemos referido a lo largo de este texto, teniendo en cuenta el contexto en el que se produjeron cargos tan serios, los dichos cargos deben ser relativizados, siendo más prudente analizar las obras y permitir que ellas hablen en nombre del artista. 
NOTAS

1 De este tema ya nos ocupamos en textos anteriores -Teresa Leonor $\mathrm{M}$. Vale, " "non piacque il disegno, che si mandò da Roma": uma questão de gosto". A circulação de informação entre Lisboa e Roma no século XVIII", en O Gosto na Arte. Idade Moderna, (Ana Duarte Rodrigues, coord.), Scribe, Lisboa, 2014 pp. 74-90; Teresa Leonor M. Vale, "Italian Baroque Sculptors and Silver: "Idea", Drawings and Models", en The Eternal Baroque. Studies in Honour of Jennifer Montagu, (Carolyn H. Miner, coord.), Skira-Sotheby's, Milán-Londres, 2015, pp. 265-278; Teresa Leonor M. Vale, "Desenho de obras de ourivesaria, no âmbito das encomendas portuguesas em Roma na primeira metade de Setecentos", en Dibujo y Ornamento. Trazas y Dibujos de Artes Decorativas entre Portugal, España, Italia, Malta y Grecia, (Sabina De Cavi, coord.), Diputación de Córdoba-De Luca Editori d'Arte, Córdoba-Roma, 2015, pp. 343-351- por lo que aquí se presenta solamente la información de relieve para la comprensión de la figura de Antonio Vendetti y de la controversia.

2 Cf. Jennifer Montagu, "The Practice of Roman Baroque Silver Sculpture", The Silver Society Journal, t. 12, 2000, pp. 18-25.

3 Cf. Jennifer Montagu, "I modelli degli argentieri", en Ori e Argenti. Capolavori del '700 da Arrighi a Valadier, (Gabriele Barucca, Jennifer Montagu, coord.), Skira, Milán, 2007, p. 56.

4 Carlo Borromeo, Instructionum Fabricae et Supellectilis Ecclesiasticae Libri II, (Stefano della Torre e Massimo Marinelli, ed.), Libreria Editrice Vaticana - Axios Group, Vaticano, 2000, p. 327 (1ª edição 1577).

5 Peter Fuhring, "Dessins d'orfèvres-sculpteurs au XVIIle siècle", en Dessins de Sculpteurs I. Troisièmes Rencontres Internationales du Salon du Dessin, (G. Scherf, coord.), Societé du Salon du Dessin, Paris, 2008, p. 49.

6 Véase Peter Fuhring, "Dessins d'orfèvres-sculpteurs au XVIIIle siècle", en Dessins de Sculpteurs I. Troisièmes Rencontres Internationales du Salon du Dessin, (G. Scherf, coord.), Societé du Salon du Dessin, Paris, 2000, pp. 53-54.
7 De Roma para Lisboa. Um Álbum para o Rei Magnânimo, (Teresa Leonor M. Vale, coord.), Santa Casa da Misericórdia-Museu de S. Roque - Scribe, Lisboa, 2015.

8 Jennifer Montagu, "The Practice of Roman Baroque Silver Sculpture", The Silver Society Journal, t. 12, 2000, pp. 18-25.

9 Valadier. Three Generations of Roman Goldsmiths, Artemis Group, Londres, 1991, cat. 62 y Jennifer Montagu, "I modelli degli argentieri", en Ori e Argenti. Capolavori del '700 da Arrighi a Valadier, (Gabriele Barucca, Jennifer Montagu, coord.), Skira, Milán, 2007, p 55

10 Jennifer Montagu, Alessandro Algardi, Yale University Press, New Haven-Londres, 1985, p. 321 e L.C.33.

11 Jennifer Montagu, "The Practice of Roman Baroque Silver Sculpture", The Silver Society Journal, t. 12, 2000, p. 25; véase también Aldo Vitali, "Note tecniche sugli argenti romani del Settecento", en Ori e Argenti. Capolavori del '700 da Arrighi a Valadier, (Gabriele Barucca, Jennifer Montagu, coord.), Skira, Milán, 2007, pp. 67-79.

12 Como los de los talleres de Giovanni Giardini, con fecha de 10 de febrero, 1722 (Archivio di Stato di Roma, 30 Not. Cap. Uff. 10, busta 391), de Michele Carlier de 30 de mayo, 1724 (A.S.R., 30 Not. Cap. Uff. 15, busta 419), de Francesco de Martini de 29 de junio, 1732 (A.S.R., 30 Not. Cap. Uff. 10, busta 422), de Giacomo Pozzi de 5 de marzo, 1735 (A.S.R., 30 Not. Cap. Uff. 6, busta 310), o de Giacomo Giardini, de 10 de mayo, 1739 (A.S.R., 30 Not. Cap. Uff. 10, busta 444), todos referidos por Jennifer Montagu, Antonio Arrighi, a silversmith and bronze founder in Baroque Rome, Tau Editrice, Todi, 2009, p. 146.

13 Como sabemos que ocurre en el caso genovés - cf. Franco Boggero, Farida Simonetti, L'Argenteria Genovese del Settecento, Banca Carige-Fondazione Carige-Umberto Allemandi \& C., Génova-Turim, 2007, p. 42.

${ }^{14}$ Véase como ejemplo los cálices de Antonio Arrighi e Mattia Venturesi (en particular, a nivel de los pies), en el Museo Diocesano de Ancona y en la iglesia parroquial de Ostia Vetere, respectivamente en Ori e Argenti. Capolavori del '700 da Arrighi a Valadier, (Gabriele Barucca, Jennifer Montagu, coord.), Skira, Milán, 2007, pp. 58 e 59.

15 Jennifer Montagu, "Artists as Collectors of Sculpture in Baroque Rome", en Collecting Sculpture in Early Modern Europe, (Nicholas Penny, Eike D. Schmidt, coord.), National Gallery of Art-Yale University Press, WashingtonNew Haven e Londres, 2008, pp. 279289; y también Jennifer Montagu, "The Practice of Roman Baroque Silver Sculpture", The Silver Society Journal, t. 12, 2000, p. 55 y Cristiano Giometti, Museo Nazionale del Palazzo di Venezia. Sculture in Terracotta, Gangemi Editore, Roma, 2011, pp. 18-21.

16 Véase como ejemplo una de las cuentas del platero Antonio Arrighi, relativa a obras realizadas para la Corona portuguesa: Biblioteca da Ajuda (Lisboa), Ms. 49-VIII-13, fol.os 139-147v. y 192-194.

17 Teresa Leonor M. Vale, "Italian Baroque Sculptors and Silver: "Idea", Drawings and Models", en The Eternal Baroque. Studies in Honour of Jennifer Montagu, (Carolyn H. Miner, ed.), SkiraSotheby's, Milán-Londres, 2015, pp. 265-278.

18 José Manuel Cruz Valdovinos, "Platería", en Historia de las Artes Aplicadas e Industriales en España, (Antonio Bonet Correa, coord.), Cátedra, Madrid, 1982, p. 139, José Luis Barrio Moya, "Antonio Vendetti, Platero y Broncista Italiano del Siglo XVIII, y sus obras en Madrid", Anales del Instituto de Estudios Madrileños, t. XXX, Madrid, 1991, p. 100 e Fernando Martín, "Influencia Italiana en la Platería Madrileña", Antologia di Belle Arti. Studi sul Settecento I. Nova Série, № 55-58, Turín, 1998, pp. 122-123.

19 Esta síntesis biográfica de Antonio Vendetti se basa en: Costantino Bulgari, Argentieri, Gemmari e Orafi d'Italia. Lorenzo del Turco, Roma, 1958, 1959, t. II, pp. 523-524, Anna Bulgari Calissoni, Argentieri, Gemmari e Orafi di Roma, Fratelli Palombi Editori, Roma, 1987, p. 435 y Alvar González-Palacios, "Open Queries: Short Notes About the Decorative Arts in Rome", en Art in Rome in the Eighteenth Century, (Edgar Peters Bowron, Joseph J. Rishel, coord.), 
Merrell-Philadelphia Museum of Art, Filadélfia, 2000, p. 187.

20 Anna Maria Pedrocchi, Argenti Sacri nelle Chiese di Roma dal XV al XIX Secolo, "L'Erma" di Bretschneider, Roma, 2010, p. 88, № 169.

21 Anna Bulgari Calissoni, Argentieri, Gemmari e Orafi di Roma, Fratelli Palombi Editori, Roma, 1987, p. 39.

22 Anna Bulgari Calissoni, Argentieri, Gemmari e Orafi di Roma, Fratelli Palombi Editori, Roma, 1987, p. 37.

23 Ori e Argenti. Capolavori del '700 da Arrighi a Valadier, (Gabriele Barucca, Jennifer Montagu, coord.), Skira, Milán, 2007, cat. 54, 136, 232.

24 Anna Bulgari Calissoni, Argentieri, Gemmari e Orafi di Roma, Fratelli Palombi Editori, Roma, 1987, p. 39.

25 Margherita Spinucci, "139-Antonio Vendetti (Cottanello in Sabina 1699-Roma 1796; patentato 1737) Busto reliquiario di san Biagio", en Sculture Preziose. Oreficeria Sacra nel lazio dal XIII al XVIII Secolo, (Benedetta Montevecchi, coord.), Gangemi Editore, Roma, 2015, pp. 176 (fotografia) y 238.

${ }^{26}$ B.A., Ms. 49-VIII-27, Doc. 8 (4552).

27 Véase lo que ya escribimos sobre estas sacras en: Teresa Leonor $\mathrm{M}$. Vale, "Da forma e da preciosidade da palavra. A presença de sacras barrocas italianas na celebração religiosa do Portugal de Setecentos", en Actas do III Colóquio Português de Ourivesaria, (Gonçalo Vasconcelos e Sousa, coord.), Centro de Investigação em Ciências e Tecnologias das Artes da Universidade Católica Portuguesa, Porto, 2012, pp. 173-189 y A Capela de S. João Batista da Igreja de S. Roque. A Encomenda, a Obra, as Coleções, (Teresa Leonor M. Vale, coord.), Santa Casa da Misericórdia de Lisboa-Imprensa Nacional Casa da Moeda, Lisboa, pp. 221-222.

28 Anna Bulgari Calissoni, Argentieri, Gemmari e Orafi di Roma, Fratelli Palombi Editori, Roma, 1987, p. 39; Teresa Leonor M. Vale, De Roma para Lisboa. Um álbum para o rei Magnânimo. Roteiro, Santa Casa da Misericórdia de Lisboa-Museu de S. Roque, 2015, p. 42, No 44 .

29 Roberto Valeriani, "Antonio Vendetti", en Art in Rome in the Eighteenth
Century, (Edgar Peters Bowron, Joseph J. Rishel, coord.), Merrell-Philadelphia Museum of Art, Filadélfia, 2000, p. 186 afirma que sobre la realización de esta obra escribe Luca Antonio Chracas, Diario Ordinario. Roma, 1749 , lo que no ocurre.

30 Esta parte del texto es deudora de la generosa colaboración del Profesor Francisco Javier Montalvo Martín, de la Universidad de Alcalá, que nos ha enviado gran parte de la bibliografía necesaria.

31 José Luis Barrio Moya, "Antonio Vendetti, Platero y Broncista Italiano del Siglo XVIII, y sus obras en Madrid". En: Anales del Instituto de Estudios Madrileños, t. XXX, Madrid, 1991, pp. 101 y 107-109.

${ }^{32}$ Fernando Martín, Catalogo de la Plata del Patrimonio Nacional. Madrid: Editorial Patrimonio Nacional, 1987, p. 389 y José Luis Barrio Moya, "Antonio Vendetti, Platero y Broncista Italiano del Siglo XVIII, y sus obras en Madrid", Anales del Instituto de Estudios Madrileños, t. XXX, Madrid, 1991, p. 102.

33 José Luis Barrio Moya, "Antonio Vendetti, Platero y Broncista Italiano del Siglo XVIII, y sus obras en Madrid". En: Anales del Instituto de Estudios Madrileños, t. XXX, Madrid, 1991, p. 103.

${ }^{34}$ Arturo Hernández Otero, "El altar mayor de la Catedral de Segovia", Estudios Segovianos, t. IV, Segovia, 1952, pp. 280-322 y José Luis Barrio Moya, "Antonio Vendetti, Platero y Broncista Italiano del Siglo XVIII, y sus obras en Madrid", Anales del Instituto de Estudios Madrileños, t. XXX, Madrid, 1991, p. 103.

35 Francisco Javier Montalvo Martín, La platería religiosa de la catedral de Segovia. Memoria de licenciatura inédita, 1983, pp. 174-183.

36 Sobre las obras en bronce y en otros metales realizadas por Vendetti en España véase José Manuel Cruz Valdovinos, "Obras de los plateros adornistas Vendetti, Giardoni y Ferroni para la Capilla del Real Palacio de Aranjuez", Anales de Estudios Madrileños, XXXVI, Madrid, 1996, p. 612.

${ }^{37}$ Fernando Martín, Catalogo de la Plata del Patrimonio Nacional. Madrid: Editorial Patrimonio Nacional, 1987, p. 389.
38 Fernando Martín, Catalogo de la Plata del Patrimonio Nacional. Madrid: Editorial Patrimonio Nacional, 1987, p. 389 y José Luis Barrio Moya, "Antonio Vendetti, Platero y Broncista Italiano del Siglo XVIII, y sus obras en Madrid", Anales del Instituto de Estudios Madrileños, t. XXX, Madrid, 1991, p. 103.

39 Fernando Martín, Catalogo de la Plata del Patrimonio Nacional. Madrid: Editorial Patrimonio Nacional, 1987, p. 87 , cat. 56.

40 José Manuel Cruz Valdovinos, Francisco Javier Montalvo Martín, Valor y Lucimiento. Platería en la Comunidad de Madrid, Comunidad de Madrid, Madrid, 2004, pp. 168-169.

41 Y también con otros tres cálices, según Javier Montalvo Martín: en Ajofrín (Toledo), Cortegana (Huelva) de 1771 y trinitarias del Toboso (Ciudad Real) de 1779 - José Manuel Cruz Valdovinos, Francisco Javier Montalvo Martín, Valor y Lucimiento. Platería en la Comunidad de Madrid, Comunidad de Madrid, Madrid, 2004, p. 168

42 José Manuel Cruz Valdovinos, "Obras de los plateros adornistas Vendetti, Giardoni y Ferroni para la Capilla del Real Palacio de Aranjuez", Anales de Estudios Madrileños, XXXVI, Madrid, 1996, pp. 611-612.

43 José Luis Barrio Moya, "Antonio Vendetti, Platero y Broncista Italiano del Siglo XVIII, y sus obras en Madrid", Anales del Instituto de Estudios Madrileños, t. XXX, Madrid, 1991, p. 104.

44 Enrique Pardo Canalis, "Escultores Italianos de los Siglos XVIII y XIX", Archivo Español de Arte. XXVIII, Madrid, 1955, p. 98, José Luis Barrio Moya, "Antonio Vendetti, Platero y Broncista Italiano del Siglo XVIII, y sus obras en Madrid", Anales del Instituto de Estudios Madrileños, t. XXX, Madrid, 1991, p. 104, establece que el apoyo solicitado fue concedido en 1794, lo que no parece verosímil, porque desde 1780 Antonio Vendetti se encontraba de regreso en Roma y en su taller en la ciudad pontificia, donde contaría con la colaboración de su hijo Angelo (que regresó con el padre, mientras que su hermano, Fabio, permaneció en Madrid).

45 Cf. B.A., Ms. 49-VIII-21, No 196, documento ya referido por Jennifer Montagu, Gold, Silver and Bronze. 
Metal Sculpture of the Roman Baroque, Yale University Press, New Haven-Londres, 1996, pp. 168-169.

46 Sobre estos relicarios (ahora desaparecidos) y los otros, similares, de Carlo Guarnieri, cf. Jennifer Montagu, Gold, Silver and Bronze. Metal Sculpture of the Roman Baroque, Yale University Press, New Haven-Londres, 1996, pp. 169-172, Teresa Leonor M. Vale, "Da forma e da preciosidade da palavra. A presença de sacras barrocas italianas na celebração religiosa do Portugal de Setecentos", en Actas do III Colóquio Português de Ourivesaria, (Gonçalo Vasconcelos e Sousa, coord.), Centro de Investigação em Ciências e Tecnologias das Artes da Universidade Católica Portuguesa, Porto, 2012, pp. 211-213, Teresa Leonor M. Vale, "Eighteenthcentury Roman Silver for the chapel of St John the Baptist of the church of S. Roque, Lisbon", The Burlington Magazine, CLII, N 1.289, Londres, 2010, pp. 528-535 y A Capela de S. João Batista da Igreja de S. Roque. A Encomenda, a Obra, as Coleções, (Teresa Leonor M. Vale, coord.), Santa Casa da Misericórdia de Lisboa-Imprensa Nacional Casa da Moeda, Lisboa, 2015, pp. 216-219.

47 Jennifer Montagu, Gold, Silver and Bronze. Metal Sculpture of the Roman Baroque, Yale University Press, New Haven-Londres, 1996, pp. 157160, Teresa Leonor M. Vale, "119. Carlo Guarnieri, Relicário de São Félix", "120. Carlo Guarnieri, Relicário de Santo Urbano", en A Arquitectura Imaginária. Pintura, Escultura, Artes Decorativas, (António Filipe Pimentel, coord.), Museu Nacional de Arte Antiga-Imprensa Nacional-Casa da Moeda, Lisboa, 2012, pp. 211-213 y Teresa Leonor M. Vale,"Roman Baroque Silver for the Patriarchate of Lisbon", The Burlington Magazine, CLV, No 1.323, Londres, 2013, pp. 384-389.

48 Jennifer Montagu, Gold, Silver and Bronze. Metal Sculpture of the Roman Baroque, Yale University Press,
New Haven-Londres, 1996 y Jennifer Montagu, "Gagliardi versus Sampajo, the Case for the Defence", Antologia di Belle Arti. Studi Romani. I. Nova Série, No 67-70, Turim, 2004, pp. 75-92.

${ }^{49}$ Jennifer Montagu, "Gagliardi versus Sampajo, the Case for the Defence", Antologia di Belle Arti. Studi Romani. I. Nova Série, № 67-70, Turim, 2004, p. 78.

50 Costantino Bulgari, Argentieri, Gemmari e Orafi d'Italia. Lorenzo del Turco, Roma, 1958, 1959, t. I, p. 117.

51 Archivo Histórico de Protocolos de Madrid. Protocolos 17992, fol. ${ }^{\circ} 302-$ 303. Escribano Miguel Casimiro Pardo, publicado por José Luis Barrio Moya, "Antonio Vendetti, Platero y Broncista Italiano del Siglo XVIII, y sus obras en Madrid", Anales del Instituto de Estudios Madrileños, t. XXX, Madrid, 1991, pp. 107-109.

52 Véase como ejemplo B.A., Ms. 49-VIII-19, fol. 87, Ms. 49-VIII-21, fol. 60, Ms. 49-VIII-22, fol. ${ }^{\circ}$ s 65, 70 y 487. 


\section{REFERENCIAS}

Barucca, Gabriele, and Jennifer Montagu. 2007. Ori e Argenti. Capolavori del '700 da Arrighi a Valadier. Milan: Skira.

Barrio Moya, José Luis. 1991. "Antonio Vendetti, Platero y Broncista Italiano del Siglo XVIII, y sus obras en Madrid." Anales del Instituto de Estudios Madrileños, t. XXX: 99-109

Boggero, Franco, and Farida Simonetti. 2007. L'Argenteria Genovese del Settecento. Genoa-Turin: Banca Carige-Fondazione CarigeUmberto Allemandi \& Co.

Borromeo, Carlo. 2000. Instructionum Fabricae et Supellectilis Ecclesiasticae Libri II, edited by Stefano della Torre e Massimo Marinelli. Vatican: Libreria Editrice Vaticana - Axios Group (1st edition 1577).

Bulgari, Costantino. 1958-1959. Argentieri, Gemmari e Orafi d'Italia. Rome: Lorenzo del Turco

Bulgari Calissoni, Anna. 1987. Argentieri, Gemmari e Orafi di Roma. Rome: Fratelli Palombi Editori

Chracas, Luca Antonio. 1749. Diario Ordinario. Rome.

Cruz Valdovinos, José Manuel. 1982. "Platería." In Historia de las Artes Aplicadas e Industriales en España, edited by Antonio Bonet Correa, 65-158. Madrid: Cátedra.

Cruz Valdovinos, José Manuel. 1996. “Obras de los plateros adornistas Vendetti, Giardoni y Ferroni para la Capilla del Real Palacio de Aranjuez." Anales de Estudios Madrileños, XXXVI: 607-624.

Cruz Valdovinos, José Manuel, and Francisco Javier Montalvo Martín. 2004. Valor y Lucimiento. Platería en la Comunidad de Madrid. Madrid: Comunidad de Madrid.

Giometti, Cristiano. 2001. Museo Nazionale del Palazzo di Venezia. Sculture in Terracotta. Rome: Gangemi Editore.

Fuhring, Peter. 2008. "Dessins d'orfèvres-sculpteurs au XVIIle siècle." In Dessins de Sculpteurs I. Troisièmes Rencontres Internationales $d u$
Salon du Dessin, edited by G. Scherf, 49-60. Paris: Societé du Salon du Dessin.

González-Palacios, Alvar. 2000. "Open Queries: Short Notes About the Decorative Arts in Rome." In Art in Rome in the Eighteenth Century, edited by Edgar Peters Bowron and Joseph J. Rishel, 157-163. Philadelphia: Merrell-Philadelphia Museum of Art.

Hernández Otero, Arturo. 1952. "El altar mayor de la Catedral de Segovia." Estudios Segovianos, t. IV: 280-322.

Martín, Fernando. 1987. Catálogo de la Plata del Patrimonio Nacional. Madrid: Editorial Patrimonio Nacional.

Martín, Fernando. 1998. "Influencia Italiana en la Platería Madrileña." Antologia di Belle Arti. Studi sul Settecento / 55-58: 122-123.

Martín, Fernando. 2003. "Plateros italianos en España." In Estudios de Platería. San Eloy, edited by Jesús Rivas Carmona, 329-344. Murcia: Universidad de Murcia.

Montagu, Jennifer. 1985. Alessandro Algardi. New Haven-Londres: Yale University Press.

Montagu, Jennifer. 1996. Gold, Silver and Bronze. Metal Sculpture of the Roman Baroque. New Haven-London: Yale University Press

Montagu, Jennifer. 2000. "The Practice of Roman Baroque Silver Sculpture." The Silver Society Journal, t. 12: 18-25.

Montagu, Jennifer. 2004. "Gagliardi versus Sampajo, the Case for the Defence." Antologia di Belle Arti. Studi Romani. I, n 67-70: 75-92.

Montagu, Jennifer. 2007. "I modelli degli argentieri." In Ori e Argenti. Capolavori del '700 da Arrighi a Valadier, edited by Gabriele Barucca and Jennifer Montagu, 53-61. Milan: Skira.

Montagu, Jennifer. 2008. "Artists as Collectors of Sculpture in Baroque Rome." In Collecting Sculpture in Early Modern Europe, edited by Nicholas Penny and Eike D. Schmidt, 279-289. Washington-New Haven and London: National Gallery of Art-Yale University Press.

Montagu, Jennifer. 2009. Antonio Arrighi, a silversmith and bronze founder in Baroque Rome. Todi: Tau Editrice. 
Montalvo Martín, Francisco Javier. 1983. La platería religiosa de la catedral de Segovia. Memoria de Licenciatura inédita. Universidad de Alcalá.

Nieva Soto, Pilar. 2007. "Adornos de plata y bronce en las camas reales de los Reyes Carlos IV y Fernando VII." In Estudios de Platería. San Eloy, edited by Jesús Rivas Carmona, 243-260. Murcia: Universidad de Murcia.

Pardo Canalis, Enrique. 1955. "Escultores Italianos de los Siglos XVIII y XIX." Archivo Español de Arte. XXVIII: 97-116.

Pedrocchi, Anna Maria. 2010. Argenti Sacri nelle Chiese di Roma dal XV al XIX Secolo. Rome:"L’Erma" di Bretschneider

Spinucci, Margherita. 2015. "139-Antonio Vendetti (Cottanello in Sabina 1699-Roma 1796; patentato 1737) Busto reliquiario di san Biagio." In Sculture Preziose. Oreficeria Sacra nel lazio dal XIII al XVIII Secolo, edited by Benedetta Montevecchi, 238. Rome: Gangemi Editore

Valadier. Three Generations of Roman Goldsmiths. 1991. London: Artemis Group.

Vale, Teresa Leonor M. 2010. "Eighteenth-century Roman Silver for the chapel of St John the Baptist of the church of S. Roque, Lisbon." The Burlington Magazine, CLII, no. 1.289: 528-535.

Vale, Teresa Leonor M. 2012. "119. Carlo Guarnieri, Relicário de São Félix", "120. Carlo Guarnieri, Relicário de Santo Urbano." In A Arquitectura Imaginária. Pintura, Escultura, Artes Decorativas, edited by António Filipe Pimentel, 211-213. Lisbon: Museu Nacional de Arte Antiga-Imprensa Nacional-Casa da Moeda.

Vale, Teresa Leonor M. 2012. “Da forma e da preciosidade da palavra. A presença de sacras barrocas italianas na celebração religiosa do Portugal de Setecentos." In Actas do III Colóquio Português de Ourivesaria, edited by Gonçalo Vasconcelos e Sousa, 173-189. Porto: Centro de Investigação em Ciências e Tecnologias das Artes da Universidade Católica Portuguesa.
Vale, Teresa Leonor M. 2013. "Roman Baroque Silver for the Patriarchate of Lisbon". The Burlington Magazine, CLV, no. 1.323: 384-389.

Vale, Teresa Leonor M. 2014. " "non piacque il disegno, che si mandò da Roma": uma questão de gosto. A circulação de informação entre Lisboa e Roma no século XVIII." In O Gosto na Arte. Idade Moderna, edited by Ana Duarte Rodrigues, 74-90. Lisbon: Scribe.

Vale, Teresa Leonor M., ed. 2015. A Capela de S. João Batista da Igreja de S. Roque. A Encomenda, a Obra, as Coleções. Lisbon: Santa Casa da Misericórdia de Lisboa-Imprensa Nacional Casa da Moeda.

Vale, Teresa Leonor M. 2015. "Desenho de obras de ourivesaria, no âmbito das encomendas portuguesas em Roma na primeira metade de Setecentos." In Dibujo y Ornamento. Trazas y Dibujos de Artes Decorativas entre Portugal, España, Italia, Malta y Grecia, edited by Sabina De Cavi, 343-51. Cordoba-Rome: Diputación de Córdoba-De Luca Editori d'Arte.

Vale, Teresa Leonor M. 2015. "Italian Baroque Sculptors and Silver: "Idea", Drawings and Models." In The Eternal Baroque. Studies in Honour of Jennifer Montagu, edited by Carolyn H. Miner, 265-278. Milan-London, SkiraSotheby's.

Vale, Teresa Leonor M. 2015. De Roma para Lisboa. Um Álbum para o Rei Magnânimo. Lisbon: Santa Casa da Misericórdia-Museu de S. Roque - Scribe.

Valeriani, Roberto. 2000. "Antonio Vendetti." In Art in Rome in the Eighteenth Century, edited by Edgar Peters Bowron, Joseph J. Rishel, 186. Philadelphia: Merrell-Philadelphia Museum of Art.

Vitali, Aldo. 2007. "Note tecniche sugli argenti romani del Settecento." In Ori e Argenti. Capolavori del '700 da Arrighi a Valadier, edited by Gabriele Barucca and Jennifer Montagu, 67-79. Milan: Skira. 